\title{
Curving Performance of Straddle-Type Monorail Vehicle with Single- Axle Bogies Based on Spatial Multi-Body Dynamic Analysis
}

\author{
Junchao ZHOU*, Zixue DU**, Zhen YANG***, Zhouzhou XU**** \\ *School of Mechanical Engineering and the Sichuan Provincial Key Lab of Process Equipment and Control, Sichuan \\ University of Science and Engineering, Zigong, Sichuan,643000, PR. China, E-mail: zhou1987g@163.com \\ **Institute of Urban Rail, Chongqing Jiaotong University, Chong Qing 400074, PR. China, E-mail: aaadzx@163.com \\ ***Institute of Urban Rail, Chongqing Jiao tong University, Chong Qing 400074, PR. China, E-mail: $21930315 @ q q . c o m$ \\ ****Institute of Urban Rail, Chongqing Jiao tong University, Chong Qing 400074, PR. China, E-mail: 33243665@qq.com \\ cross ref $h$ ttp://dx.doi.org/10.5755/j02.mech.22930
}

\section{Introduction}

With the rapid development of social economy and the acceleration of urbanization, urban transportation is facing tremendous pressure, especially in large cities. Urban rail transit, with advantages of small air pollution and large traffic volume, is a relatively economical public rail transit system. Straddle-type monorail, as a unique technology, energy saving and environmental protection, is different from the subway running mode of urban rail transit system. There are two kinds of straddle-type monorails: one is dual-axis bogies, the other is a new single-axis bogie. Brazil's Bombardier Monorail 300 and China's BYD are using this new type of single-axle rail vehicle. Bombardier's INNOVIA Monorail 300 System permitted transit authorities to now consider monorail as a mainstream contender to meet their mass transit requirements [1]. Monorail 300 vehicles with single-axle bogies has better adapt to road lines. Their turning radius can reach $46 \mathrm{~m}$, but that of the traditional Monorail vehicle is only $100 \mathrm{~m}$. Moreover, the vehicle height is $4.05 \mathrm{~m}$, which is $1.25 \mathrm{~m}$ lower than Chongqing monorail vehicles.

The dynamic model of monorail vehicle ,taking into account the influence of track irregularity on the tire fore and the curving dynamics of a monorail car was simulated by using these dynamic models [2].The reference [3, 4] discussed dynamic characteristics of AGT vehicle with single axle bogies compared with conventional steering system and the results compared to that of the field test .A three-dimensional means of analysis was proposed for the bridge--vehicle interaction to investigate the dynamic responses of a steel girder bridge and vehicles [5-7]. The dynamic response analysis procedure is proposed and applied to investigate the dynamic responses of monorail bridges [7, 8].The dynamic system of 15-degrees-of-freedom for traffic-induced vibration of a monorail bridge and train was proposed $[9,10]$.The dynamic model of the coupled system of the straddle type monorail train and the track beam was proposed by Chongqing vehicle with two-axle bodies [11, 12]. Based on the finite element and multi-body dynamics, dynamic interaction of the monorail-bridge system is studied [13]. A mathematical model of a straddle type monorail vehicle was developed in order to study its stability and the effect of tyre model techniques on its dynamic response [14].

Numerous on the relation between dynamic model and dynamic parameters have been carried out in research and development phase of conventional straddle-type monorail with two-axle bogies. In this paper, the spatial coupling dynamics model of straddle-type monorail with the singleaxle bogies is proposed by the multi-body dynamics.

The other structure of the article is as follows: First, the constructions of the straddle-type monorail with the single-axle bogies; Secondly, introduces the modeling process of dynamic model of straddle-type monorail with the singleaxle bogies in detail; The third part is the results and discussion.

2. Spatial coupling dynamic model of straddle-type monorail vehicle with single-axle bogies

2.1. Straddle-type monorail vehicle with single-axle bogies

The straddle-type Vehicle with Single-axle bogies includes 4 running tires, 8 guide tires and 4 steady tires. The running tires are nitrogen-filled high-pressure tires. Guide tires and steady tires are rubber tires filled with air. The running tires are connected with the body by vertical and lateral shock absorbers and hydraulic springs. There are two independent axles and two load-bearing bogies in each vehicle body. All bogies are powered by traction motors and disc brakes. Independent bogies and air springs are used to provide better ride comfort [15]. The single-axle bogies can guarantee excellent load-bearing tire shape and turning ability. The air spring is used for the secondary suspension of the body and bogie. The straddletype monorail dynamic model with single-axle is illustrated in the reference [16].

The main differences between single-axle bogies and two-axle bogies are: a) The number of running tire axles of single-axle bogies is only half of that of two-axle bogies; b) The single-axle bogies don't have longitudinal traction rubber pile but the traction rod and balance bar that transmit longitudinal load and moment of bogies and body. The comparison of the straddle-type monorail model is shown in Fig. 1. The vehicle parameters are illustrated in the Table 1.

In order to reduce the complexity of the model and simplify the calculation, the elastic elements involved in the monorail vehicle, such as air springs, guide tires, stabilizing tires and running tire characteristics, are all modeled in linear springs in the coupling dynamics model . In the coupling dynamics model, the three DOF of the single-axle bogies and the front and rear bogies are considered, including the three degrees of freedom of the movement of the telescopic, traverse, and up and down, and DOF for roll, nodding, and yawing movements. the total of freedom is 34 degrees of freedom. 
Table1

Properties of monorail train

\begin{tabular}{|l|l|l|l|l|l|}
\hline Body & & Bogie & & $\begin{array}{l}\text { Ge- } \\
\text { ome- } \\
\text { try }\end{array}$ & \\
\hline$m_{11}$ & $14.000 \mathrm{~kg}$ & $\begin{array}{l}m_{21}, \\
m_{22}\end{array}$ & $2400 \mathrm{~kg}$ & $L z_{1}$ & $0.63 \mathrm{~m}$ \\
\hline$I_{x 11}$ & $44.377 \mathrm{~kg} \cdot \mathrm{m}^{2}$ & $\begin{array}{l}I_{x 21}, \\
I_{x 22}\end{array}$ & $1104 \mathrm{~kg} \cdot \mathrm{m}^{2}$ & $L z_{2}$ & $0.15 \mathrm{~m}$ \\
\hline$I_{y 11}$ & $\begin{array}{l}225.892 \\
\mathrm{~kg} \cdot \mathrm{m}^{2}\end{array}$ & $\begin{array}{l}I_{y 21}, \\
I_{y 22}\end{array}$ & $1195 \mathrm{~kg} \cdot \mathrm{m}^{2}$ & $L z_{3}$ & $0.152 \mathrm{~m}$ \\
\hline$I_{z 11}$ & $\begin{array}{l}195.402 \\
\mathrm{~kg} \cdot \mathrm{m}^{2}\end{array}$ & $\begin{array}{l}I_{z 21}, \\
I_{z 22}\end{array}$ & $2230 \mathrm{~kg} \cdot \mathrm{m}^{2}$ & $L z_{4}$ & $0.39 \mathrm{~m}$ \\
\hline & $\begin{array}{l}K_{2111}, \\
K_{2112}\end{array}$ & $1061000 \mathrm{~N} / \mathrm{m}$ & $L z_{5}$ & $0.39 \mathrm{~m}$ \\
\hline & $\begin{array}{l}K_{3111}, \\
K_{3112}\end{array}$ & $33333 \mathrm{~N} / \mathrm{m}$ & $L y_{2}$ & $0.525 \mathrm{~m}$ \\
\hline & $\begin{array}{l}C_{4111}, \\
C_{4112}\end{array}$ & $33333 \mathrm{~N} / \mathrm{m}$ & $L y_{4}$ & $0.2 \mathrm{~m}$ \\
\hline
\end{tabular}
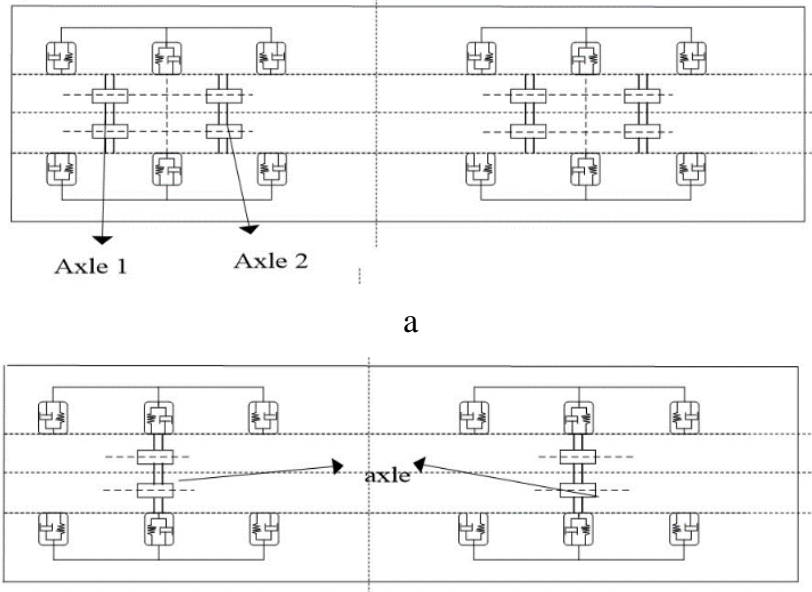

$\mathrm{b}$

Fig. 1 Comparison of Straddle-type Monorail Models: a) two-axle of monorail vehicle; b) one-axle of monorail vehicle

The formula for the kinetic energy $T$, potential energy $U$ and virtual work of a monorail vehicle running on a track beam $\delta W$ are as follows [17]:

$$
\left\{\begin{array}{l}
T=\frac{1}{2}\left(\begin{array}{l}
m_{11} \dot{z}_{11}^{2}+m_{11} \dot{y}_{11}^{2}+I_{x 11} \dot{\theta}_{y 11}^{2}+I_{z 11}^{2} \\
+\sum_{i=1}^{2}\left(m_{2 i} \dot{z}_{2 i}^{2}+m_{2 i} \dot{y}_{2 i}^{2}+I_{v x} \dot{\theta}_{x 2 i}^{2}+I_{v y} \dot{\theta}_{y 2 i}^{2}+I_{v z} \dot{\theta}_{z 2 i}^{2}\right)
\end{array}\right), \\
U=\frac{1}{2}\left(\sum_{i=1}^{2} \sum_{j=1}^{2} \sum_{n=1}^{2}\left\{\begin{array}{l}
K_{1 i j n} R_{1 i j n}^{2} \Delta \delta_{1 j}+K_{2 i j n} R_{2 i j n}^{2} \\
+K_{3 i j n} R_{3 i j n}^{2}+K_{4 i j n} R_{4 i j n}^{2} \Delta \delta_{1 j}
\end{array}\right\}+\sum_{i=1}^{2} K_{5 i 11} R_{5 i 11}^{2}\right)
\end{array}\right),
$$

where: $m_{11}$ is mass of vehicle body; $x, y, z, \theta$ are respectively the longitudinal, lateral, vertical and angular displacement; $K_{1 i j n}, C_{1 i j n}$ are the vertical stiffness and vertical damping of air spring; $K_{2 i j n}, C_{2 i j n}$ are the stiffness and damping of the running tire; $K_{3 i n j}, C_{3 i j n}$ are the stiffness and damping of the guide tires; $K_{4 i n j}, C_{4 i j n}$ are the stiffness and damping of the steady tire; $K_{5 i n j}, C_{5 i j n}$ are the lateral stiffness and lateral damping of air spring; $i$ is bogie posi- tion $(i=1,2$ respectively represents the front and rear bogies); $j$ is the longitudinal position of the tire $(j=1,2$ respectively represents the front and rear tires); $\mathrm{n}$ is the left and right tire ( $n=1,2$ respectively represents the left and right tires); $R_{1 i j n} R_{2 i j n} R_{3 i j n} R_{4 i j n} R_{5 i j n}$ are the relative displacements of spring and the shock absorber in $x, y, z$ directions. $\Delta \delta_{j}$ is the Kronecker function $(r=1,2,3,4,5)$.

$$
R_{i j n}=\left\{\begin{array}{l}
Z_{11}-(-1)^{i} \theta_{y 11} L_{x i}-(-1)^{n} L_{y 1} \theta_{x 11}-Z_{i 2}+(-1)^{n} L_{y(\mathrm{i}+1)} \theta_{x i 2} \\
i=1,2 ; j=1 ; n=1,2 \\
Z_{12}-(-1)^{n} L_{y 2} \theta_{x 12} \quad i=1 ; j=2 ; n=1 \\
Z_{22}+(-1)^{i} L_{x 3} \theta_{y 2}-(-1)^{n} L_{y 3} \theta_{x 22} \quad i=2,3 ; j=2 ; n=1,2 \\
0 \quad \text { other }
\end{array}, .\right.
$$

In the equation $\theta_{x 11}$ means the roll angle of the car body; $\theta_{y 11}$ means the nodding angle of the car body; $\theta_{x i 2}$ means roll angle of the bogie; $\theta_{y 2}$ means the nodding angle of the bogie; $L_{x m}$ means the longitudinal distance from the body mass center to the front and rear bogie air spring installed position; $L_{y(i+1)}$ means the lateral distance from the body mass center to the installed position of the air spring.
In order to cooperate with the suspension with low transverse rigidity, a horizontal stop is set. The transverse stop is fixed on the frame with 4 bolts, and the backing plate is used to adjust the clearance between the lateral stop and the center pin. The nonlinear dynamic model of the horizontal stop is: 


$$
F=\left\{\begin{array}{lr}
0 & \text { if } q>q_{1} \\
K\left(q_{1}-q\right)^{e}-c_{\max } \dot{q} * \operatorname{step}\left(q, q_{1}-d, q_{1}, 0\right) & \text { if } q \leq q_{1}
\end{array}\right. \text {, }
$$

where: $K$ is the stiffness coefficient; $e$ is the exponent of th e force; $c_{\max }$ is the maximum damping coefficient; $d$ is the amount of the damping reaching the maximum value; $q_{1}$ is the threshold of the function; $q_{1}$ is the distance variable; $\dot{q}$ is the speed between two points; step is step function of ADA MS. $K=500000, e=1.01, c_{\max }=5000, q_{1}=0.081$.

\subsection{Track linear models}

The tire and track beam contact model is illustrated in the reference [18]. Considering the easement curve during driving, the longitudinal slope, the super elevation on curve, orbital joints, and turnout junction structure of entry, the orbit model consists of three segments: the straight line, the curved line and the straight line. The equation of track line is shown in the reference[19]. The track is considered to be rigid.
The Easement curve is located between a straight line and an arc curve. The Easement curve is shown in the following equation:

$$
\mathrm{p}_{T}(\sigma)=\left[\begin{array}{l}
\mathrm{x}_{\mathrm{t}}(\sigma) \\
\mathrm{y}_{\mathrm{t}}(\sigma) \\
\mathrm{z}_{\mathrm{t}}(\sigma)
\end{array}\right]=\left[\begin{array}{l}
\sigma-\frac{1 \sigma^{5}}{10 \pi^{2}} k^{5} \\
\frac{1}{6} \sigma^{3} k-\frac{1 \sigma^{7}}{84 \pi^{2}} k^{3} \\
\frac{h_{\max }-h_{\min }}{l_{c l o}} \sigma
\end{array}\right] .
$$

In the equation $k=\frac{1}{l_{c l o} R}, l_{c 0}$ is the length of the Easement curve; $h$ is the super-high value of the Easement curve; $h_{\max } h_{\min }$ are the maximum super-high value for the beginning and ending phases; $\sigma$ is the coordinate point of the track line.

The circle curve is represented by Eq. (6): where: $\Phi(\sigma)=\arctan ((d y / d \sigma) /(d x / d \sigma)) ; R$ is the radius of the circular curve.

The final line is shown in Fig 2. Setting of curve lines is illustrated in Table 2.

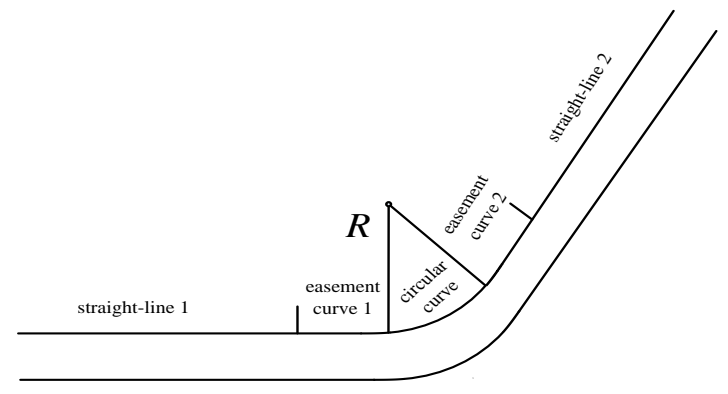

Fig. 2 Line diagram of the track

Table 2

Setting of curve lines. Unit in $\mathrm{m}$

\begin{tabular}{|l|l|l|l|l|l|l|}
\hline$R$ & $\begin{array}{l}\text { straight } \\
\text { line }\end{array}$ & $\begin{array}{l}\text { ease- } \\
\text { ment } \\
\text { curve 1 }\end{array}$ & $\begin{array}{l}\text { circu- } \\
\text { lar } \\
\text { curve }\end{array}$ & $\begin{array}{l}\text { ease- } \\
\text { ment } \\
\text { curve 2 }\end{array}$ & $\begin{array}{l}\text { straight } \\
\text { line 2 }\end{array}$ & $\begin{array}{l}\text { rail } \\
\text { width }\end{array}$ \\
\hline 46 & 100 & 12 & 46 & 12 & 100 & 0.69 \\
\hline
\end{tabular}

2.3. Dynamic model between vehicles and track beams

By combining the vehicle state equation, the orbital beam equation and the tire-rail relationship, a spatial coupled dynamic model of the vehicle, the tire, and the track beam can be obtained:
In the equation $M, C, K, B$ are respectively mass, damping, stiffness matrix and force load; $X$ is displacement vector.

By the vehicle body model, track beam model and tire-rail contact model, the spatial coupling dynamic model of single-axle bogie monorail vehicle is established by the multi-body dynamics software ADAMS.

\section{Results and discussion}

How to select the contact state between the guide tires and the track beam is a unique problem of the rail transit vehicle. The initial value of the preload of the single-axle vehicle is a key factor. The influence of the contact state of the guide tires and the rail beam on the dynamics of single axle monorail vehicle is analyzed below. Contact state includes: $3.8 \mathrm{KN}, 5.0 \mathrm{KN}, 6.2 \mathrm{KN}$ preloads with full load condition between guide tires and rail. The full load condition refers to the mass of the body is $23,180 \mathrm{~kg}$. There is no simulation considering no-load condition. Some key indicators, such as the radial force of horizontal tires (steady tires and guide tires), vehicle body roll angle, the lateral force of running tires, steering torque ,are selected for evaluating the curving performance of the vehicle.

Load process of the guide tires of front bogies with different contact states is illustrated in Fig. 3. It shows that when the guide tires presets the preload, the easement curve, the right side of the rear guide tires and the left side 
of the front guide tires are loaded, and the left side of the rear guide tires and the right side of the front guide tires are unloaded. The increase of the value is equivalent to the decreasing value of the load.

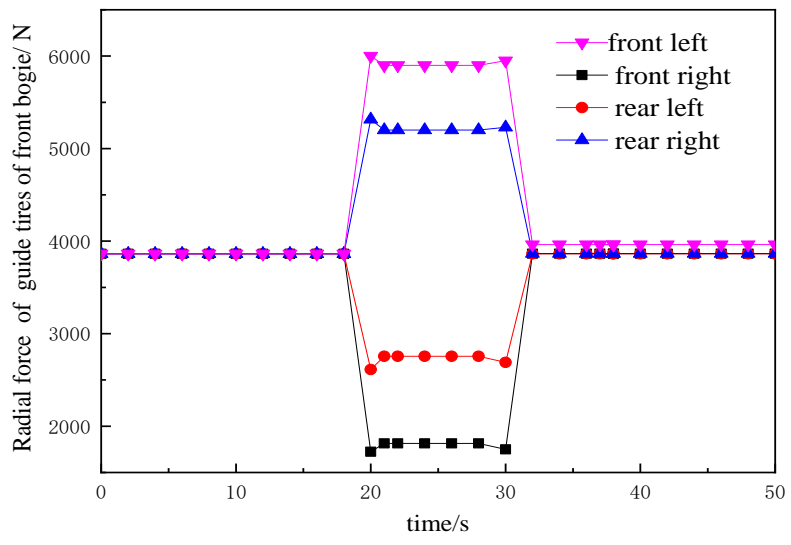

a

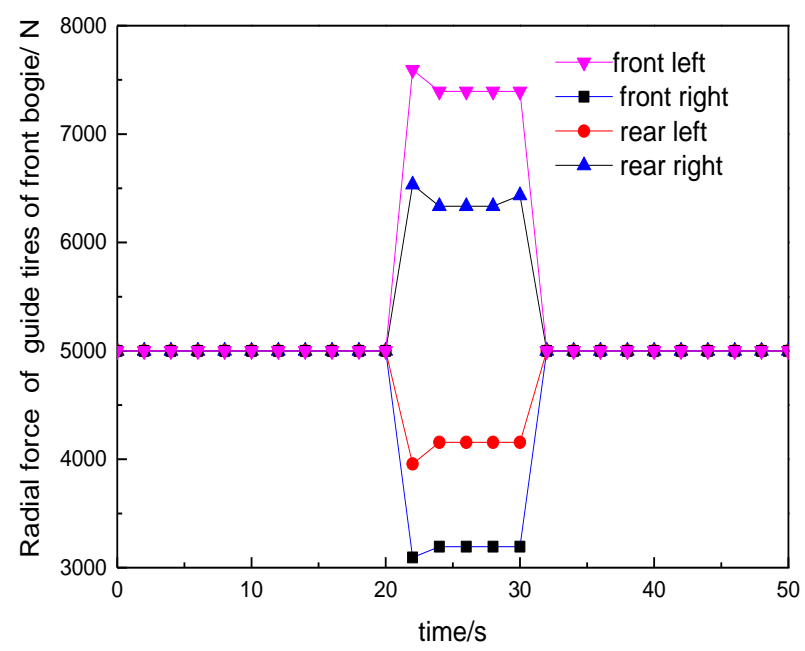

b

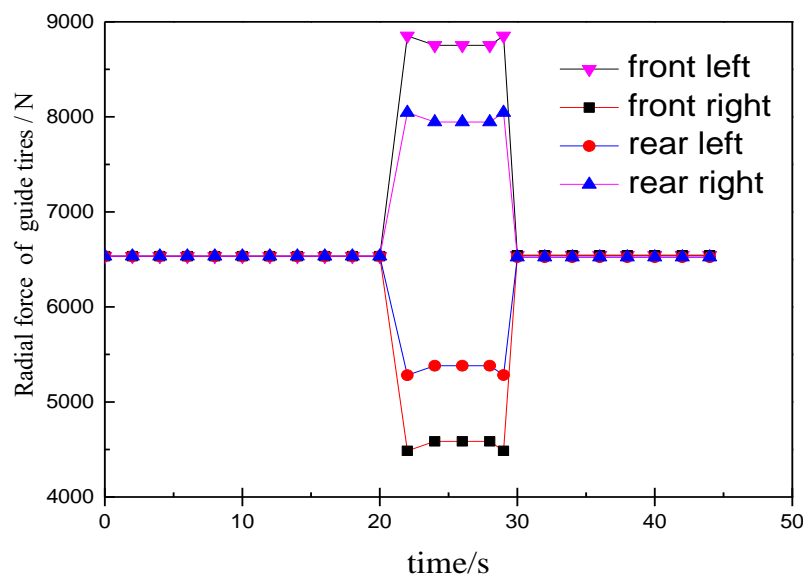

c

Fig. 3 Load process of the guide tires of front bogie with different contact states: a) preload $3.8 \mathrm{KN}$; b) preload 5.0 KN; c) preload 6.2 KN

The comparisons of the maximum radial force of the guide tires with different contact states are illustrated in Fig. 4. From Fig. 4, it can be seen that setting the initial preload obviously increases the load of the guide tires; Also, increasing the preload increases the lateral force of the tire. The greater the preload, the better the curving performance. From the curve passing and tire wear, it is recommended that preload should be 4 to $5 \mathrm{KN}$. When preloads of the guide tires and steady tires are $5 \mathrm{KN}$, the load changes of the running tire and the steady tires are illustrated in Fig. 5. The radial force of two guide tires in one side and the radial force of the steady tires in the other side are not zero at the same time, and the lateral force of the running tire is still large, and the stability of the vehicle against derailment is better. From the curve passing and tire wear, it is recommended that the preload should be $5 \mathrm{KN}$.
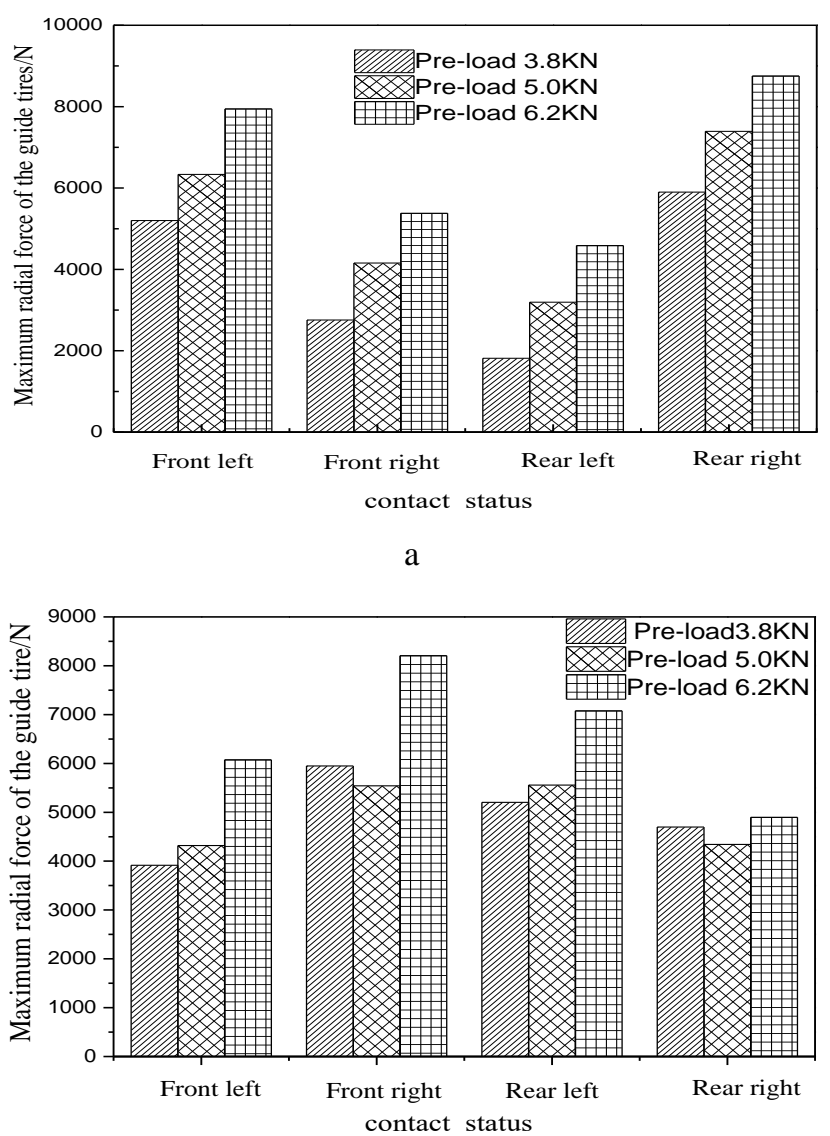

$\mathrm{b}$

Fig. 4 Comparison of the maximum radial force of the guide tires with different contact states: a) Front bogie; b) Rear bogie

When the preload of the guide tires is $5.0 \mathrm{KN}$, the radial forces of the front and rear bogie guide tires are shown in Fig. 6. It can be drawn from Fig. 6:

1) In comparison, the radial force of the front bogie is larger than that of the rear bogie, especially the front left and rear right of the front bogie, and the increase of the front left guide tires is biggest and the rear right decreases furthest. That is, the front left and rear right guide tires of the front bogie play the main guiding function when the vehicle is turning, which is same as the guiding principle of the twoaxle bogie;

2) The front left and rear right guide tires of the front bogie are subjected to a greater radial force, and the front right and rear left guide tires have a smaller radial force. In addition, when the vehicle turns, the radial forces of the four guide tires of the front bogie form a shaking mo- 
ment that causes the bogie to rotate along the track; (3) Relative to the front bogie, the rear bogie makes a right turn, so the changes of the radial forces of the four tires are contrary to those of the front bogie, and forms a heading moment opposite to the front bogie. The shaking moments of the front and rear bogies constitute the main turning force of the vehicle's good curve.
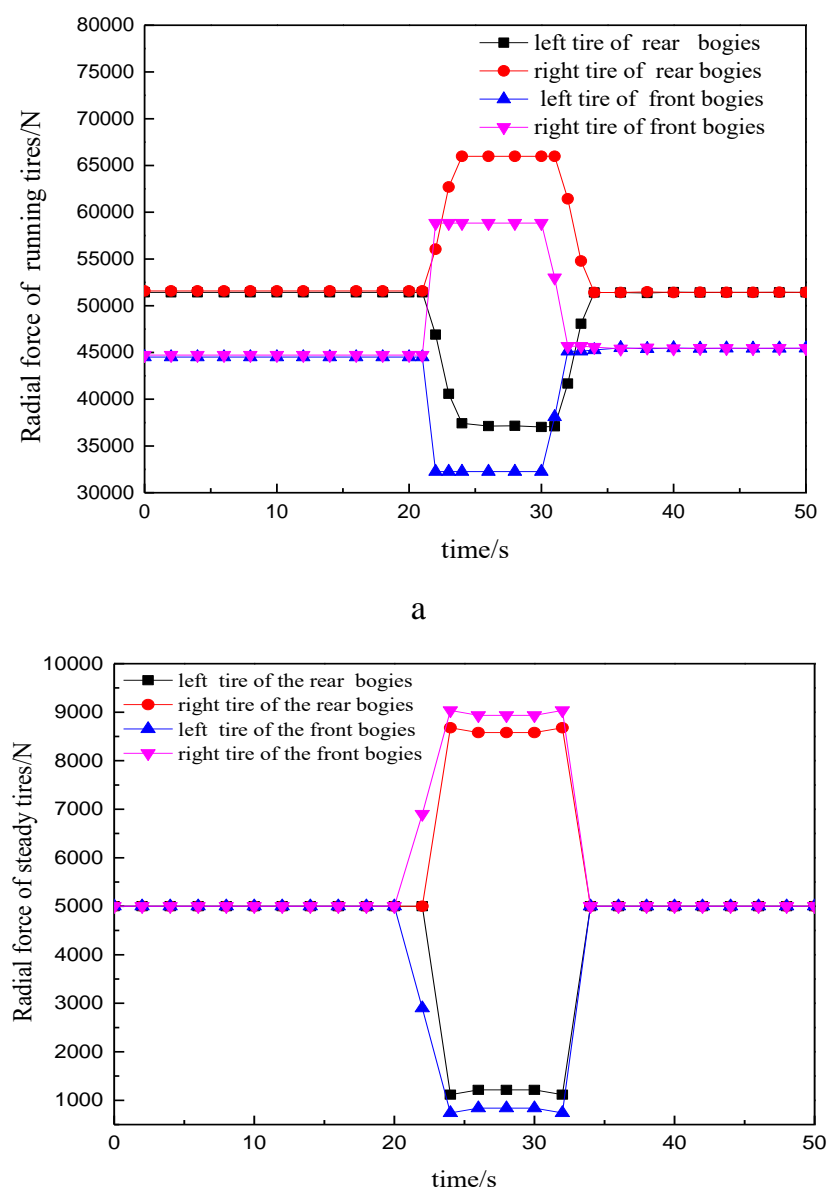

b

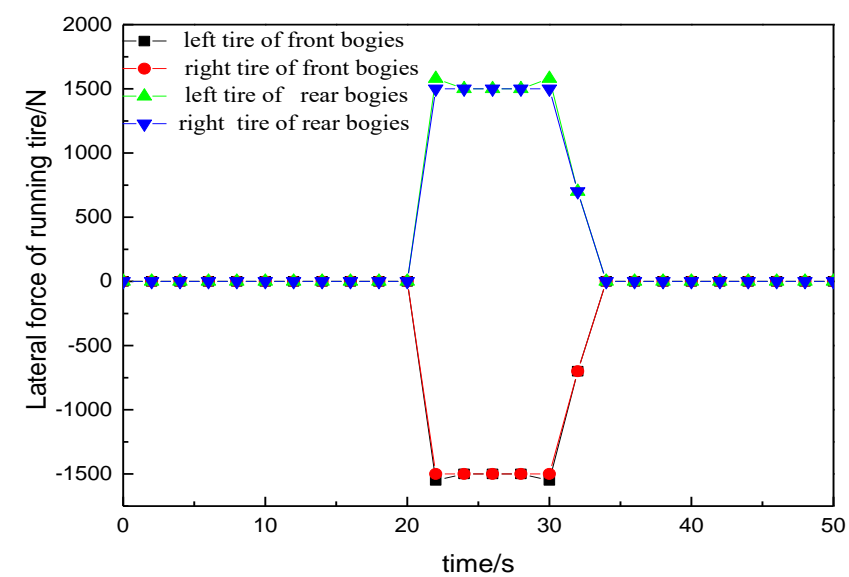

b

Fig. 5 Load changes of the running tires and steady tires: a) Tire radial force of running tires; b) Tire radial force of steady tires; c) The lateral force of running tires

Radial force of steady tires under different conditions are illustrated in Fig. 7. From Fig. 7, it can be concluded that the radial forces of the left of the steady tires increase, and the radial forces of the right decrease, but the amplitude of the increase and decrease is small, so the antioverturning moment of the steady tires is mainly to resist vehicle overturning. The single-axle bogie vehicle has the following advantages over the two-axle bogie: a good curve passing, and a minimum passing radius of $\mathrm{R} 46 \mathrm{~m}$ [1].

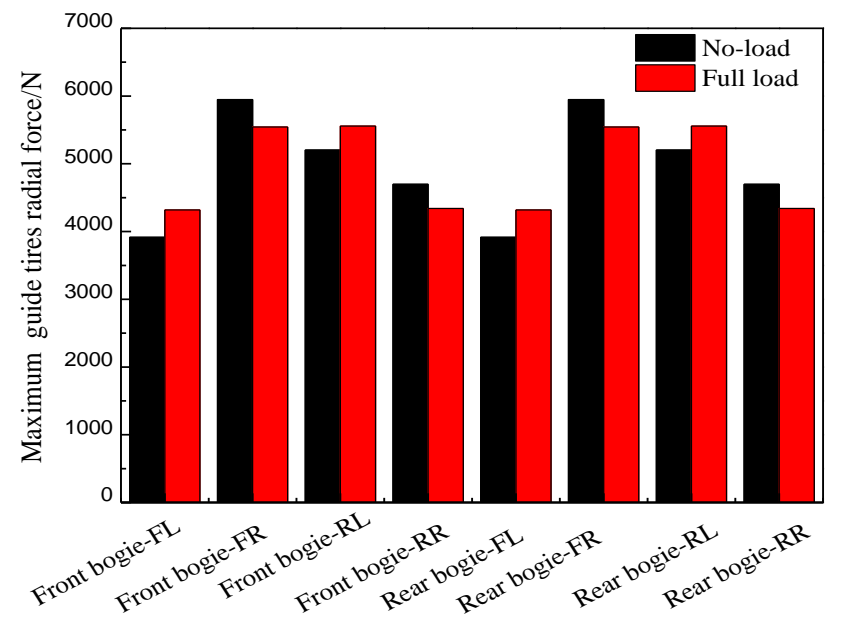

Fig. 6 Comparison of radial forces of guide tires on singleaxle bogies

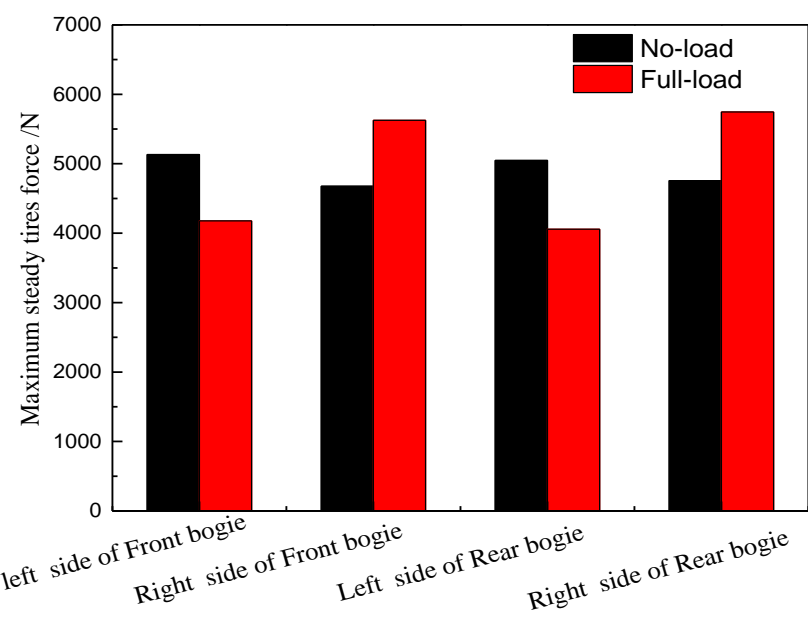

Fig. 7 Radial force of steady tires under different conditions

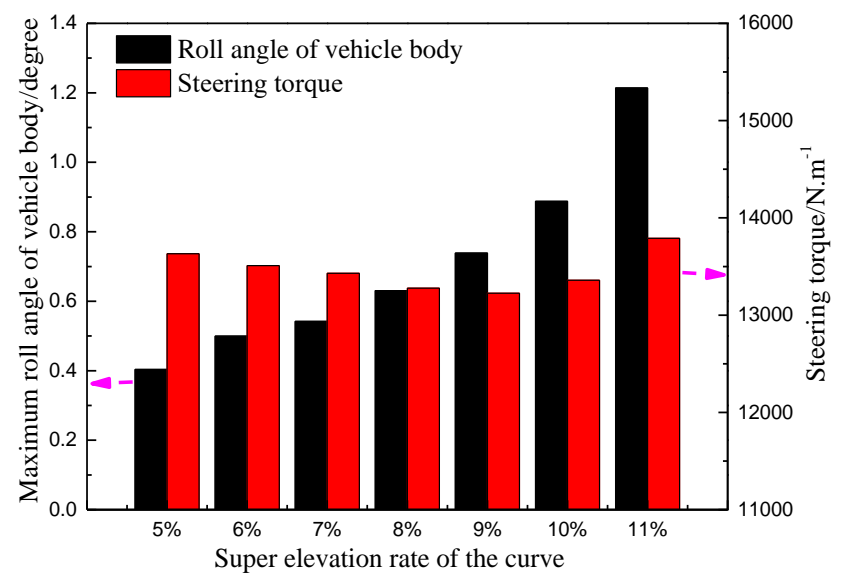

Fig. 8 The maximum roll angle of the car body and the steering torque at different super-high rates

The maximum roll angle of the car body and the steering torque at different super-high rates is illustrated in Fig. 8. It can be seen that the maximum roll angle of the car body increases with the increase of the super-high rate, 
and the steering torque decreases first and then increases with the increase of the super-high rate. Therefore, when the super-high rate of the curve is 8 to $10 \%$.

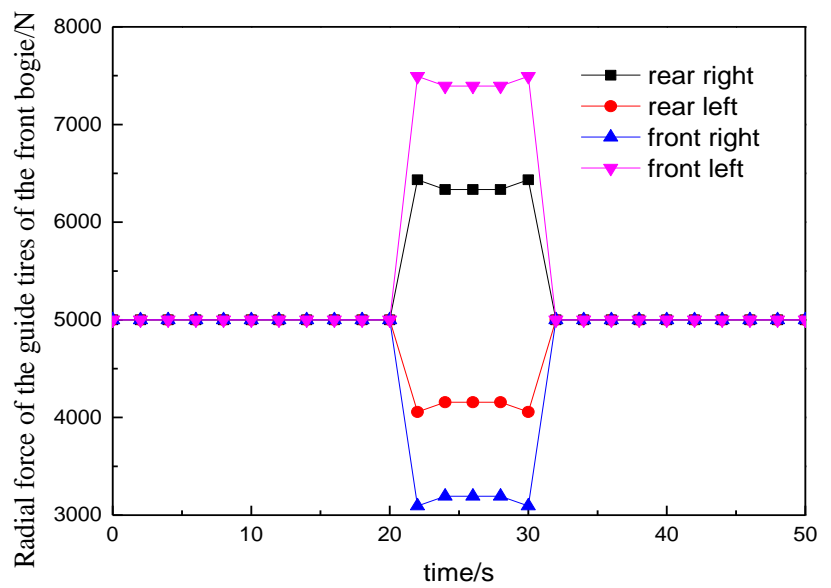

a

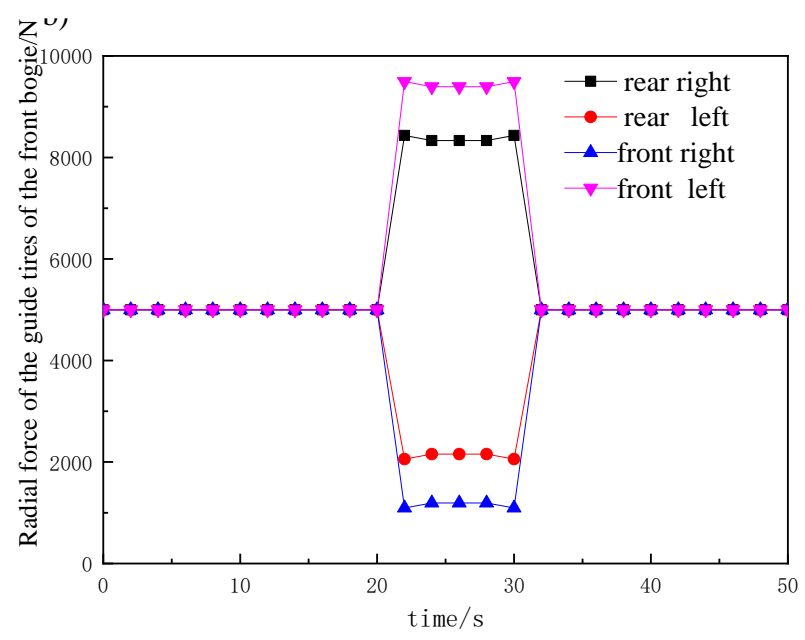

b

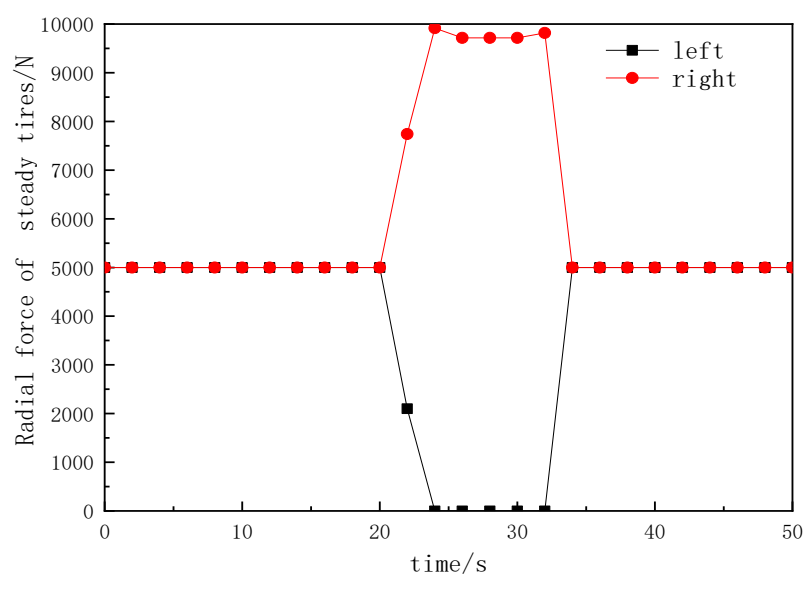

c

Fig. 9 Radial force results of the steady tires and the guide tires: a) Radial force of guide tires of the front bogie with super-high rate of $8 \%$; b) Radial force of the guide tire with super-high rate of $10 \%$; c) Radial force of steady tires with the super-high rate of $10 \%$

When the preload of the steady tires and the guide tire is $5 \mathrm{KN}$ and the vehicle passes the curves of different super-high rates of the radius $\mathrm{R} 46$ at a speed of $26 \mathrm{~km} / \mathrm{h}$. The radial force results of the steady tires and the guide tires are explained in Fig. 9. It can be seen from the figure that when the track super-high rate is $8 \%$, the radial forces of the steady tires and guide tire on the outer side of the circular curve are greater than zero, indicating that both the steady tire and guide tire are in contact with the track beam; when the track super-high rate is $10 \%$, the radial force of the steady tire on the outer side of the circular curve reduces to zero, while the radial force of the guide tire is greater than zero, indicating that the steady tire has been separated from the track beam, but the guide tire is still in contact with the track beam.

\section{Acknowledgments}

This work was supported by the Sichuan Provincial Key Lab of Process Equipment and Control [grant number GK201806].

\section{References}

1. Timan, P. E. 2015. Why monorail systems provide a great solution for metropolitan areas, Urban Rail Transit 1(1):13-25. http://dx.doi.org/10.1007/s40864-015-0001-1.

2. Goda, K.; Nishigaito, T.; Hiraishi, M.; Iwasaki, K. 2002. Improving curving performance for articulatedtype smal monorail car, Transactions of the Japan Society of Mechanical Engineers C 68(672):2410-2417.

3. Hitoshi Tsunashima, K. K. a. K. K. 2000. Dynamics of AGT vehicle with single-axle bogies, International Conference on Transportation and Traffic Studies, 67:762-769.

4. Tsunashima, H. 2003. Dynamics of automated guideway transit vehicle with single-axle bogies, Vehicle System Dynamics 39(5):365-397. http://dx.doi.org/10.1076/vesd.39.5.365.14146.

5. ChulWoo Kim, M. K.; KiBong Kim. 2005.Three-dimensional dynamic analysis for bridge-vehicle interaction with roadway roughness, Computers \& Structures 1627-1645.

http://dx.doi.org/10.1016/j.compstruc.2004.12.004.

6. Wang, H.; Zhu, E.; Chen, Z. 2017. Dynamic Response analysis of the straddle-type monorail bridge-vehicle coupling system, Urban Rail Transit 3(3):172-181. http://dx.doi.org/10.1007/s40864-017-0069-x.

7. Gou, H.; Zhou, W.; Yang, C.; Bao, Y.; Pu, Q. 2018. Dynamic response of a long-span concrete-filled steel tube tied arch bridge and the riding comfort of monorail trains, Applied Sciences 8(4):650. http://dx.doi.org/10.3390/app8040650.

8. Kim, C. W.; Kawatani, M. 2006. Effect of train dynamics on seismic response of steel monorail bridges under moderate ground motion, Earthquake Engineering and Structural Dynamics 35(10):1225-1245. http://dx.doi.org/10.1002/eqe.580.

9. Lee, C. H.; Kim, C. W.; Kawatani, M.; Nishimura, N.; Kamizono, T. 2006. Dynamic response analysis of monorail bridges under moving trains and riding comfort of trains, Engineering Structures 35(10):1225-1124. http://dx.doi.org/10.1016/j.engstruct.2005.06.014.

10. Lee, C. H.; Kawatani, M.; Kim, C. W.; Nishimura, N.; Kobayashi, Y. 2006. Dynamic response of a monorail steel bridge under a moving train, Journal of Sound and Vibration 294(3):562-579. 
http://dx.doi.org/10.1016/j.jsv.2005.12.028.

11. Ma, J.; Pu, Q.; Huo, X. 2009. Vehicle-bridge coupling vibration analysis of $\mathrm{pc}$ rail beam of straddle-type monorail transportation, Xinan Jiaotong Daxue Xuebao, Journal of Southwest Jiaotong University 44(6): 806$811+829$. http://dx.doi.org/10.3969/j.issn.02582724.2009.06.002.

12. Liu, Y. Y.; Ge, Y. M.; Yang, Y. R. 2010.Vibration characteristic of coupled system for straddle type monorail beam and train, Jiaotong Yunshu Gongcheng Xuebao, Journal of Traffic and Transportation Engineering 10(2): 46-53.

13. Naeimi, M.; Tatari, M.; Esmaeilzadeh, A.; Mehrali, M. 2015. Dynamic interaction of the monorail-bridge system using a combined finite element multibodybased model, Proceedings of the Institution of Mechanical Engineers, Part K: Journal of Multi-body Dynamics 229(2): 132-151.

http://dx.doi.org/10.1177/1464419314551189.

14. MacIel, G. P. R.; Barbosa, R. S. 2016. Monorail vehicle model to study influence of tyre modelling on overall dynamics, International Journal of Heavy Vehicle Systems 23(4): 317-332. http://dx.doi.org/10.1504/IJHVS.2016.079270.

15. Cao, D.; Song, X.; Ahmadian, M. 2011. Editors' perspectives: road vehicle suspension design, dynamics, and control, Vehicle System Dynamics 49(1-2): 3-28. http://dx.doi.org/10.1080/00423114.2010.532223.

16. Zhou, J.; Du, Z.; Yang, Z.; Xu, Z. 2020. Dynamic parameters optimization of straddle-type monorail vehicles based multiobjective collaborative optimization algorithm, Vehicle System Dynamics 58(3): 357-376. http://dx.doi.org/10.1080/00423114.2019.1578384.

17. Wen Xiao xia, D. Z.; Xu Zhouzhou; Yi Yanli; Wei Hanbing. 2017. The coupling dynamic model and vibration response of straddle type monorail vehicle, Journal of Vibration Measurement \& Diagnosis 37(3): 462-468. http://dx.doi.org/10.16450/j.cnki.issn.10046801.2017.03.007.

18. Zhou, J.; DU, Z.; YANG, Z. 2019. Dynamic response of the full-scale straddle-type monorail vehicles with single-axle bogies, Mechanics 25(1): 17-24. http://dx.doi.org/10.5755/j01.mech.25.1.21931.

19. Pombo, J., and J. A. C. 2003. General spatial curve joint for rail guided vehicles: kinematics and dynamics, Multibody System Dynamics 9(3): 237-264.

JC. Zhou, ZX. Du, Y. Zhen, ZZ. Xu

\section{CURVING PERFORMANCE OF STRADDLE-TYPE MONORAIL VEHICLE WITH SINGLE-AXLE BOGIES BASED ON SPATIAL MULTI-BODY DYNAMIC ANALYSIS}

S u m m a r y

Straddle-type monorail, as a unique technology, energy saving and environmental protection, is different from the subway of urban rail transit system. In order to study the curving performance of a new type of the straddletype monorail vehicle with single-axle bogies, the three-dimensional spatial dynamics model which consists of the vehicle model and track model designis proposed by the multibody dynamics soft ADAMS. The monorail vehicle dynamic model which consists of three types of tire -track contact model and the nonlinear model of the horizontal stop is established. Based on the dynamic model, the influences such as pre pressure and curve super-high rate parameters of the curve passing for the dynamic characteristics are discussed. The simulation results show that the suitable preload for the guide and stabilizer tires of straddle-type vehicle with single-axle bogies is $5 \mathrm{KN}$ and after selecting the appropriate pre-pressure, the super-high rate is recommended to be $8 \%-10 \%$.

Keywords: straddle-type monorail vehicle, curving performance, three-dimensional spatial dynamics, single-axle bogies, dynamics model; super-high rate parameters.

Received March 11, 2019 Accepted April 07, 2021

This article is an Open Access article distributed under the terms and conditions of the Creative Commons Attribution 4.0 (CC BY 4.0) License (http://creativecommons.org/licenses/by/4.0/). 